\title{
Recensión de la obra de Michele Tiraboschi: Persona e lavoro tra tutele e mercato. Per una nuova ontologia del lavoro nel discorso giuslavoristico, ADAPT University Press, Bergamo (Italia), 2019
}

\author{
Juan Raso-Delgue \\ Catedrático de Derecho del Trabajo y de la Seguridad Social \\ Universidad de la República (Uruguay) \\ Vice Presidente de la Sociedad Internacional \\ de Derecho del Trabajo y de la Seguridad Social \\ juanraso@redfacil.com.uy
}

Recibido: 14.06 .2020 | Aceptado: 14.06.2020

Acabo de terminar la lectura del último libro del Prof. Michele Tiraboschi: Persona e lavoro tra tutele e mercato. El argumento central de la obra es de gran actualidad en esta época de profundas transformaciones, en la que la condición humana y las tecnologías (que empujan hacia el bien y el mal) plantean un complejo debate, del que no es fácil escapar.

El camino que el Prof. Tiraboschi nos invita a recorrer está inicialmente marcado por consideraciones del escritor italiano Primo Levi, que muestran una fascinante propuesta: mirar hacia el trabajo como la principal expresión de nuestra identidad y a la vez como vehículo de nuestra inserción en el mundo. Porque el trabajo posee la doble dimensión del sufrimiento (trepalium) y de la creación. Es así que el libro plantea desde sus primeras páginas la idea de un concepto más amplio del trabajo: el trabajo no solo como oportunidad del salario, sino como principal expresión de la autorealización del hombre, que culmina en la construcción de la propia profesionalidad.

En esta línea, el enfoque del Prof. Tiraboschi me recuerda anteriores reflexiones de Mario Grandi (a quien cita), cuando refiere a "la instancia ética de revalorización de perfil subjetivo de la relación (de trabajo), animada por el intento de separar el trabajo del mundo de las cosas, para reconducirlo a la esfera existencial de la persona (a su Dasein)".

Ante un nuevo paradigma -afirma el Prof. Tiraboschi- es necesaria una nueva dimensión principista, que promueva la persona-trabajador en su dimensión social y relacional. Ante las nuevas realidades, cae -en su tradición histórica- la centralidad de la subordinación, porque vivimos "la explosión de una pluralidad de formas de trabajo". Concebir el trabajo humano afuera del mercado es una utopía, una ilusión que termina por vaciar de contenidos 
la propia acción productiva. Pero, por otra parte, someter la persona a las leyes dura del mercado, transformarla en una simple mercancía, repugna a un sistema de valores, que es propio de quieres estudian nuestra disciplina. No es posible imaginar un derecho del trabajo sin valores humanos, pero es necesario reajustar la dimensión ontológica del trabajo ante una realidad, que se transforma dinámicamente.

El Prof. Tiraboschi transita desde los grande desafíos de ayer a los de hoy, examinándolos desde una nueva construcción de valores que promueve la "instancia personalista" del trabajador: el debate en torno a la estabilidad en el "lugar de trabajo"; el cuestionamiento del mercado, planteando lo que es y lo que puede y debe ser; el pasaje del mercado de trabajo asalariado a los "mercados transicionales del trabajo" en una nueva lectura jurídica que permita una visión más actual de la relación entre la persona y el trabajo.

También cuestiona el tema de la renta básica o "reddito di cittadinanza", que se proyecta hacia "una economía del subsidio" distinta de la economía del mercado.

Y finalmente plantea con coraje el problema del trabajo sin un valor de mercado y el consiguiente debate entre el deber ser jurídico tradicional y el desafío de una nueva ontología del trabajo.

Las conclusiones apuntan a la valorización de la profesionalidad como dimensión necesaria en la relación entre la persona y el trabajo, entendiendo por profesionalidad no la simple "formación para el mercado", sino la elaboración de aquellos conocimientos y aprendizajes que conforman los proceso de "educación" de la persona. Para ello es necesario fijar la atención sobre la necesaria integración entre los recorridos educativos y los formativos con el trabajo, pero también sobre el rol que la realidad juega en la construcción de la propia empleabilidad. Más que "saber para hacer", la nueva profesionalidad se construye sobre la idea de "hacer para aprender", que conjuga en un diseño unitario la práctica con la teoría, es decir la acción con la reflexión.

Finalmente destacamos el aspecto medular de la obra: la idea de revalorizar -y no relegar el Derecho del trabajo- a través del ajuste de su sistema ontológico a la realidad de mercados "transicionales" del trabajo y que constituye -en palabras del autor"una confirmación de la persistente actualidad del paradigma originario de nuestra disciplina". Sin embargo para que el Derecho del trabajo no renuncie a su función histórica, debe ser capaz de "repensar" sus técnicas y tutelas para garantizar el justo equilibrio entre las tutelas de las personas y la eficiencia del mercado, que es un concepto que se aparta ya sea de la exaltación que de la negación del mercado.

Como agregado final, señalo el impactante dibujo de la carátula, realizado por nuestra amiga y coordinadora de la Red Cielo, Lavinia Serrani, que es una libre interpretación del cuadro Les trois camarades de Fernand Léger. 